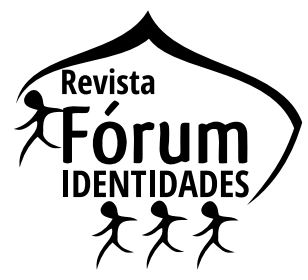

\title{
UMA ANÁLISE DE RÚTILO NADA SOB A PERSPECTIVA QUEER'
}

\author{
AN ANALYSIS OF RÚTILO NADA \\ FROM THE QUEER PERSPECTIVE
}

\author{
Rita de Kássia de Aquino Gomes ${ }^{2}$ \\ Rosanne Bezerra de Araújo ${ }^{3}$
}

\begin{abstract}
Resumo: O objetivo deste trabalho é investigar a condição relacional dos personagens Lucius e Lucas, em Rútilo Nada (1993), a partir da teoria queer. Apoiando-nos em autores como Judith Butler (2003), Eve Sedgwick (2007) e Richard Miskolci (2012), o estudo refletirá sobre importantes questões, como o regime de heteronormatividade, heterossexismo e heterossexualidade compulsória no qual os personagens de Hilda Hilst estão inseridos, analisando ainda a trajetória da relação em questão, bem como o seu desfecho, sob o viés dos estudos queer.
\end{abstract}

Palavras-chave: Teoria queer. Rútilo nada. Hilda Hilst.

\begin{abstract}
The aim of this work is to investigate the relational condition of the characters Lucius and Lucas, in Rútilo Nada (1993), from the queer theory point of view. Based on authors such as Judith Butler (2003), Eve Sedgwick (2007) and Richard Miskolci (2012), the study will reflect on important issues, such as the heteronormativity, heterosexism, and compulsory heterosexuality regime in which Hilda Hilst's characters are inserted, also analyzing the trajectory of their relationship, as well as its outcome, under the light of queer studies.
\end{abstract}

Keywords: Queer theory. Rútilo nada. Hilda Hilst.

\footnotetext{
${ }^{1}$ Artigo recebido em 13 de agosto de 2021 e aceito para publicação em 27 de setembro de 2021.

2 Doutoranda na linha de Literatura Comparada pelo Programa de Pós-graduação em Estudos da Linguagem da Universidade Federal do Rio Grande do Norte e Mestre em Estudos da Linguagem pela mesma universidade. Email: kassia.gomes.063@gmail.com. ORCID: https://orcid.org/0000-0002-4448-4778.

${ }^{3}$ Professora Associada do Departamento de Línguas e Literaturas Estrangeiras Modernas na UFRN, atuando no Curso de Letras-Inglês e no Programa de Pós-graduação em Estudos da Linguagem da mesma universidade. Doutora em Letras pela Universidade Federal da Paraíba. Email: rosanne.araujo@terra.com.br. ORCID: https://orcid. org/0000-0003-4308-3881.
} 


\section{Introdução}

A categoria da anormalidade é assunto de discussão em áreas diversas, desde a Medicina, Psicologia, Filosofia, até a Antropologia e Ciências Sociais. Em 1943, por exemplo, Georges Canguilhem publica seu importante livro, O normal e o patológico, no qual reflete sobre as distinções entre anomalia, patologia e ser doente.

Em 1975, há a publicação de um curso ministrado por Michel Foucault no Collège de France, Os anormais. Nele, Foucault apresenta figuras históricas que representaram "o anormal" em diferentes momentos: o monstro humano, o indivíduo a corrigir e o onanista. Nos anos de 1980, porém, é quando surge uma teoria cuja crítica se centra no caráter normatizador da sociedade, que lança o estigma da anormalidade àqueles que não se encaixam ou correspondem às suas políticas reguladoras: a teoria queer. Essa abordagem teórica surge na segunda metade da década de 1980, nos Estados Unidos, em resposta à falta de ação coletiva durante a crise de Aids enfrentada pelo país. Segundo Richard Miskolci (2012), sua problemática é a da abjeção, e ela torna visível as injustiças e violências implicadas na demanda do cumprimento de normas e convenções culturais, envolvidas tanto na criação dos "normais" quanto dos "anormais".

Trabalharemos aqui com a temática da homossexualidade e faz-se necessário frisar que esta é apenas uma das muitas situadas no escopo da teoria queer, já que esta lida com os corpos que não se encaixam e, por isso, são rechaçados pelo estigma. Lizandro Calegari (2016), tomando como critério básico a transgressão aos princípios do heterossexismo compulsório, identifica algumas obras como que integrando a tradição da literatura de temática homoerótica em diferentes épocas. Segundo ele, tal tradição seria constituída por obras que surgiriam já no século XIX, como O Ateneu (1888), O Cortiço (1890) e Bom Crioulo (1895), obras do século XX, como Grande Sertão: Veredas (1956) e as obras de Caio Fernando Abreu, e também por autores contemporâneos do século XXI, que tratariam do tema com uma linguagem mais direta, como é o caso de Aretusa Von, autora de Triunfo dos Pelos (2000).

Entretanto, ainda em 1994, Hilda Hilst, escritora nascida em Jaú, São Paulo, ganha o prêmio Jabuti por seu Rútilo Nada (1993), obra que, em uma abordagem transgressora, narra a história de dois homens que se envolvem, apaixonam-se e têm suas vidas desgraçadas por esse relacionamento. Hilst ficou conhecida pelos temas controversos e linguagem licenciosa de seus livros e é incluída por Arturo Gouveia (2010) no rol de escritores que retratam a coisificação das pessoas no século XX, revelada através da técnica narrativa do fluxo da consciência, que expõe as turbulências interiores dos personagens sem a verbalização tradicional por parte do narrador - o que resulta em uma minimização da ação e ampliação de formas escriturais mais caóticas. 
O presente trabalho tem como objetivo analisar Rútilo Nada (1993) sob a perspectiva da teoria queer, observando como os protagonistas do conto de Hilst quebram o pacto com os dispositivos reguladores da matriz heterossexual, desestabilizando as categorias de gênero e sendo relegados a um lugar de objeção.

No tocante à metodologia, trata-se de uma pesquisa bibliográfica. Inicialmente, veremos, a partir da análise de trechos específicos da obra, como os conceitos de heterossexismo, heteronormatividade e heterossexualidade compulsória se encaixam no meio social do qual os personagens Lucius e Lucas fazem parte. A heterossexualidade é tomada como verdade absoluta quando da sexualidade dos sujeitos da trama? O modelo binário pautado no masculino e feminino permeia as relações amorosas e sexuais na narrativa? $O$ regime heterossexual é imposto aos personagens?

Num segundo momento, refletiremos a respeito da categoria do abjeto, verificando de que maneira os protagonistas de Rútilo Nada, ao desviarem da norma sexual vigente, são relegados à abjeção. Que tipo de tratamento social é dispensado aos dois homens quando o vínculo que têm um com o outro se anuncia? Relacionaremos ainda as questões trazidas no livro de Hilst com as noções que atravessam o armário enquanto dispositivo da vida de pessoas gays, refletindo sobre as tensões que emergem da decisão de tornar aberta a sexualidade diante dos prejuízos que acometem não só elas, mas as pessoas que fazem parte de seu convívio.

Finalmente, discutiremos como Rútilo Nada toca em uma questão crucial da teoria queer, a desestabilização das categorias pautadas na matriz heterossexual, observando ainda como a narrativa dos personagens contribui para a contestação do caráter naturalizante do sexo e do gênero. Para fins de aporte teórico faremos uso dos estudos de Richard Miskolci (2012), Judith Butler (2003), Eve Sedgwick (2007) e Berenice Bento (2015).

\section{O truísmo da heterossexualidade}

Rútilo Nada, escrito em 1993, é narrado, em primeira pessoa, pelo personagem Lucius, por meio do fluxo da consciência - técnica que provoca a quebra da unidade temporal - numa mistura constante entre passado e presente. A narrativa começa in media res, com Lucius em desespero sobre o caixão de Lucas, um garoto de 20 anos, que descobrimos ser namorado de sua filha e também seu amante. Os dois homens se apaixonaram e mantiveram um caso em segredo, até que o pai de Lucius - um banqueiro direitista e conservador - desconfia dos dois e contrata capangas para que Lucas seja surrado e violentado. O rapaz vem a cometer suicídio logo depois. Temos, portanto, como temática principal do conto a relação amorosa entre dois homens. 
Richard Miskolci (2012) traz a diferenciação entre três conceitos importantes que perpassam o meio social no qual vivemos e que serão relevantes para a discussão de Rútilo Nada (1993) aqui apresentada. O primeiro deles é o de heterossexismo. Este seria a pressuposição de que todos são ou deveriam ser heterossexuais. Na narrativa de Hilda Hilst, todo conflito se dá pelo fato de a heterossexualidade ser considerada um axioma, e Hilst insere isso até mesmo em pequenos detalhes.

Um exemplo é quando Lucius - ao ser retirado do velório em direção à rua, carregado sem forças e em exasperação - põe-se a gritar o nome de Lucas. As pessoas que assistem à cena do lado de fora da rua inferem: "ah, era o filho, é? Foi o filho dele que morreu?" (HILST, 2003, p. 89) Apesar da diferença de idade, Lucius não era um senhor para ser tomado tão somente como pai, mas um homem de apenas 35 anos. Essas pessoas, como possibilidade outra, talvez pudessem inferir que se tratasse de um amigo, um irmão, pois um homem interpelando dessa forma um outro nome masculino não poderia ser o caso de uma relação passional. Homens não têm namorados ou amantes do mesmo sexo, já que são heterossexuais.

O segundo conceito que Miskolci (2012) distingue dentro da matriz heterossexual é o de heteronormatividade. O autor nos diz que esta é a ordem sexual do presente, fundada no modelo heterossexual, familiar e reprodutivo. Judith Butler (2003) nos diz que esse modelo permeia até as relações não heterossexuais. Um exemplo polêmico levantado por ela é o de quando a militância luta pela legalização do casamento homossexual. Butler questiona o porquê de os gays desejarem repetir o mesmo "formato" familiar imposto pela tradição patriarcal. Deveriam perceber que ao segui-lo terminam por reforçar a estrutura que os exclui. Por que, então, as pessoas gays dão poder às instituições de tal maneira que para além da legitimidade patrimonial, o que lhes garante certa segurança, elas também as colocam na posição de legitimar os seus afetos? Isso se daria por causa da ordem sexual sob a qual vivemos: a heteronormatividade.

Em Rútilo observamos tal ambivalência em vários momentos, quando mesmo ao falar da relação entre dois homens, o binarismo masculino e feminino, enquanto relação sexual, é posto. Em uma das falas do pai de Lucius temos:

[...] ou você imagina que ninguém sabia, crápula, canalha, tua sórdida ligação [...] aquele crapulazinha namorou minha neta para poder ficar perto de você. gosta de cu seu canalha? gosta de merda? Fez-se também de mulherzinha com o moço machão? ele só pode ter sido teu macho porque teve a decência de se dar um tiro na cabeça, mate-se também seu desgraçado mate-se (HILST, 2003, p. 87). 
Em outro momento, quando os capangas mandados para dar a surra em Lucas o violam sexualmente, um deles diz: "começa chupando a minha pica enquanto o meu amigo te usa feito dona” (HILST, 2003, p. 97). Percebemos aqui que, mesmo ao se tratar da relação entre duas pessoas do mesmo sexo, o modelo heteronormativo persiste e tende-se a querer que uma delas faça as vezes do papel da mulher na relação enquanto a outra atende ao papel do homem. Geralmente, aqueles ligados ao papel feminino são os assujeitados e submissos, enquanto os que aderem à masculinidade imperam na virilidade e poder.

Miskolci (2012) traz finalmente o conceito de heterossexualidade compulsória, que seria a imposição, como modelo, dessas relações amorosas ou sexuais entre pessoas do sexo oposto. Nós saímos, portanto, do campo da pressuposição do heterossexismo, ou seja, todos são heterossexuais, para o âmbito do dever, obrigação: todos têm que ser heterossexuais.

Ora, em Rútilo Nada (1993) o conflito é gerado quando o pai de Lucius vem a desconfiar do seu envolvimento com Lucas e o confronta violentamente, pois não concebe que o filho saia da ordem estabelecida. O próprio imperativo irredutível que lança ao filho para que siga o exemplo do amante e se mate denota essa impossibilidade de se viver fora do que é normatizado: se não se adequa à ordem vigente, ponha um fim a si mesmo. Isso nos leva a discutir esse lugar, ou não-lugar, de rechaça do qual trata a teoria queer: a abjeção.

\section{$O$ rutilante abjeto}

Butler (2003) afirma que o meio social demanda uma correspondência entre sexo-gênero-desejo e prática sexual, que convergiria para sujeitos de identidades coerentes. Aqueles corpos que quebram ou desestabilizam essa coerência são rebaixados à categoria do intolerável, do abjeto. Estes corpos têm sua humanidade posta em xeque e sua materialidade vista como nulidade dentro da matriz cultural. A partir daí, podemos enxergar as forças autoritárias e preconceituosas que Miskolci (2012) diz produzirem as experiências de abjeção, vergonha e estigma. Para ele, em termos sociais, a abjeção "constitui a experiencia de ser temido e recusado com repugnância, pois sua própria existência ameaça uma visão homogênea e estável do que é a comunidade” (MISKOLCI, 2012, p. 24).

Em uma de suas descrições, ao ser retirado do velório e arrastado para a calçada, Lucius relata:

[...] estou caindo e ao meu redor as caras pétreas, quem são? amigos? minha filha adolescente? meu pai? teus jovens amigos? Caras graníticas, ódio mudo e vergonha, palavras que vêm de longe, evanescentes, mas tão nítidas como fulgentes estiletes, palavras de supostos éticos Humanos: 
Podemos ver o lugar de desprezo designado a Lucius a partir de então. $\mathrm{Na}$ mesma cena, o personagem por vezes também chega a mencionar escarros lançados em sua direção. É interessante atentar para o "Humanos" grafado com "H", em caixa alta. Ele nos remete a uma certa autoridade, oriunda também do peso do adjetivo que lhe é atribuído. Uma vez éticos, os tais Humanos são, assim, pessoas com postura exemplar, baseada nos valores de uma moral determinante de um meio comandado por uma matriz heterossexual. O Humanos, com $h$ maiúsculo, também nos remete sonoramente ao dito presente no imaginário popular "Homem com h maiúsculo". Não seria inoportuno considerar que tal deixa sonora poderia apontar para a imagem de Lucius, descoberto como homem gay, sendo escorraçado por um meio masculino, por ter renunciado ao que eles acreditam ser a masculinidade.

Mary Douglas, em 1966, escreve um importante livro para a antropologia chamado Pureza e Perigo: Ensaio sobre as noções de poluição e tabu. Aqui ela desenvolve um estudo a partir das noções de pureza e impureza e dos rituais de purificações de algumas culturas para refletir sobre a visão de ordem social. Douglas observa como socialmente impõe-se um padrão de organização ambiente e como questões relacionadas à sujeira, limpeza e higiene se articulam com rituais de coesão do corpo físico e a política. Miskolci (2012) interpreta o estudo de Mary Douglas a partir do viés da abjeção, enfatizando como a antropóloga demonstra que aqueles que são considerados impuros, incorretos, ou, nos termos atuais, anormais tendem a extirpar a impureza de si, geralmente de maneiras dolorosas.

Após ser surrado e violentado pelos capangas do pai de Lucius, despido e humilhado, como foi deixado, Lucas escreve uma longa carta de despedida a Lucius e decide extirpar de si a "impureza" apontada e, naquele momento, marcada como violência em seu corpo, retirando a própria vida: "Antes da sombra, Lucius, quero dizer da dor de não ter sido igual a todos." (HILST, 2003, p. 98).

É relevante atentarmo-nos para como a ideia de impureza, abjeção e nojo perpetrada pela cultura sobre aqueles que tensionam ou desobedecem a estrutura normatizadora atravessa também esses sujeitos. Por vezes, a palavra nojo é proferida no conto pelos dois protagonistas para descrever aquilo que sentiram ao perceberem que estavam se envolvendo com alguém do mesmo sexo. $\mathrm{O}$ nojo seria um sintoma da cultura introjetada no sujeito agindo como censora.

Entretanto, Freud nos mostra em seus Três Ensaios Sobre a Sexualidade (1905), com seu conceito de trieb, como a pulsão, cujo único objetivo é a satisfação, supera nojo, moral e vergonha. O prazer da pulsão sexual está em usar 
sua força para suplantar o nojo (p. 144), rivalizando, assim, com a estrutura egóico-cultural. No conto, ao descrever a primeira vez que se viu fazendo sexo oral em Lucas, Lucius diz: "Viscoso. Cintilante. Pela primeira vez o meu olhar encontrava a junção do nojo e da beleza” (HILST, 2003, p. 96). Já Lucas, em sua carta deixada para Lucius, declara:

Quando nos beijamos naquela antiquíssima tarde, a consciência de estar beijando um homem foi quase intolerável, mas foi também um sol se adentrando na boca, e na luz azulada desse sol havia uma friez [sic] de água de fonte, uma diminuta entre as rochas, e beijei tua boca como qualquer homem beijaria a boca do riso, da volúpia, depois de anos de inocência e austeridade (HILST, 2003, p. 99).

Também esse trecho, com a metáfora do sol usada por Hilda, reforça o paradoxo que se estabelece constantemente no conto a partir da alusão à ideia de luz. A palavra rútilo, do título, vem de brilho, cintilação, luzente, no entanto é imediatamente seguida do substantivo "nada". Já os nomes dos personagens, Lucius e Lucas, derivam do latim e ambos significam "iluminado" ou "aquele que tem luz". Os protagonistas, porém, acabam rechaçados à abjeção e tornando-se intoleráveis por viverem uma sexualidade não condizente com as normas da ordem heteronormativa. Tende-se a se apagar a luz que incomoda.

\section{O armário, o binarismo naturalizante e a desestabilização das categorias}

Para Eve Sedgwick (2007) todos os prejuízos em torno da sexualidade de uma pessoa gay, em um meio dominado pela heteronormatividade, é o que faz com que esta esteja calculando e recalculando constantemente a sua relação com o armário. A autora define o armário como sendo uma metáfora controversa sobre um regime contraditório de privacidade e revelações, público e privado, e tem atuado como dispositivo regulador de lésbicas e gays.

Em seu livro $A$ epistemologia do armário, Sedgwick (2007) correlaciona a homossexualidade com a história de Ester para mostrar que o armário é indicativo de homofobia de uma forma que não acontece em outros tipos de opressões. As opressões fundadas em gênero, idade, raça, possuem um estigma visível, já a opressão advinda da sexualidade seria mais parecida com as étnicas/culturais/ religiosas, pois o sujeito, nesses casos, teria ao menos certo controle sobre o conhecimento das outras pessoas em relação à sua pertença a determinado grupo, daí o paralelo com a história de Ester, ao sair do armário para seu marido enquanto judia, e o sujeito homossexual, ao sair do armário enquanto pessoa gay.

No entanto, a autora atenta para o fato de que, diferente de Ester - que não temia que a sua identidade judia pudesse prejudicar de alguma forma o seu 
marido caso ele descobrisse, uma vez que apenas ela e o seu povo morreriam, mas nada aconteceria com ele -, as pessoas homossexuais não temem apenas por si, mas também por aqueles a quem amam. Quando elas saem do armário, suas famílias se veem também com suas reputações ameaçadas, e a violência que recai sobre quem se assume, respinga naqueles que convivem em seu entorno. Por isso não é incomum, diz Sedgwick, que quando alguém homossexual saia do armário, sua família entre. Ela pontua que:

quando pessoas gays se assumem em uma sociedade homofóbica, talvez especialmente para os pais ou cônjuges, é com consciência de um potencial de sério prejuízo provavelmente nas duas direções. E por isso assumir-se não acaba com a relação de ninguém com o armário, inclusive, de maneira turbulenta, com o armário do outro (SEDGWICK, 2007, p. 39).

No conto de Hilst, o pai de Lucius o acusa de arruinar a sua reputação: “anos de decência e de luta por água abaixo e eu um banqueiro, com que cara que você acha que eu vou aparecer diante de meus amigos, ou você imagina que ninguém sabia, crápula, canalha” (HILST, 2003, p. 87). Portanto, o problema não era somente Lucius estar se relacionando com um homem, mas o que todos pensariam a respeito disso quando este, até então, segredo fosse revelado, e o que isso acarretaria às pessoas ligadas a ele.

Grande parte das polêmicas em torno do armário são decorrentes da concepção naturalizada das identidades que permeiam os corpos. Para Berenice Bento (2015), ninguém nasce com aquilo que se atribui, de forma comportamental, ao gênero masculino e ao gênero feminino, mas cada sociedade elabora os padrões comportamentais para cada gênero:

Gênero talvez seja uma das categorias primeiras que são interiorizadas. Ninguém sabe precisar quando aprendeu que o fato de ter um pênis ou uma vagina seria o definidor do seu comportamento. A forma como a sociedade constrói e define o que é do gênero feminino e do gênero masculino é uma das primeiras verdades construídas e reproduzidas pela sociedade (BENTO, 2015, p. 52).

Berenice pontua que o "ser homem" ou "ser mulher" não se reduz aos caracteres sexuais, mas incluem um conjunto de elementos que são produzidos e compartilhados e que perpassam a moral e o comportamento. Estendendo ao gênero a fala que Durkheim (1989) faz sobre as categorias de tempo e espaço, a autora nos diz que como desempenham um papel preponderante na forma como compreendemos e apreendemos o mundo, as categorias estão de tal forma naturalizadas na sociedade que seu caráter histórico pode ser confundido como sendo imanente à natureza humana. 
Judith Butler também parte da abordagem não naturalizante e vai além ao dizer que "talvez o próprio construto chamado "sexo" seja tão culturalmente construído quanto o gênero" (BUTLER, 2003, p. 30). Para Butler a identidade é performativamente constituída, podendo a performance se dar em qualquer corpo, o que sugere uma descontinuidade radical entre os corpos sexuados e os gêneros culturalmente constituídos.

A visão naturalizada da identidade de gênero pode ser percebida em praticamente todo o desenlace de Rútilo Nada (1993). Como vimos anteriormente, o pai de Lucius não apenas se contrapõe ao relacionamento do filho com Lucas, mas põe em xeque sua masculinidade a todo tempo, lançando em sua direção o que considera impropérios, ao atribuir ao filho expressões relacionadas ao gênero feminino. Porém, podemos vislumbrar, em alguns momentos do conto, passagens que vão ao encontro da desestabilização das categorias, defendida por Butler, e da discussão sobre o caráter não natural das identidades, ambos temas cruciais da teoria queer.

O narrador, em seu fluxo da consciência, anuncia: "Farpas pontudas emergindo do corpo dos conceitos. Antes o conceito redondo. Liso" (HILST, 2003, p. 87). Com o desenrolar da narração de Lucius, podemos perceber que o conceito referido é aquele concebido primariamente para designar o que seria um "homem" ou uma "mulher". Diante de seu conflito frente ao desejo por alguém do mesmo sexo, Lucius passa a questionar a sua identidade, antes tida como natural. Ele ironiza dizendo "carne de Lucius antes era mansa e tépida, brioso corpo de antes tão educado respondendo rápido a qualquer afago, de mulheres naturalmente, ah sim, naturalmente, mulheres [...]" (HILST, 2003, p. 91 grifo nosso).

$\mathrm{O}$ narrador-personagem tende a obnubilar as fronteiras entre os gêneros, de forma a transitar em seu discurso entre um e outro, dando a ideia do gênero enquanto variável fluída e do caráter flexível do desejo:

Tua macia rouquidão. Igualzinha à macia rouquidão de uma sonhada mulher, só que não eras uma mulher, eras o meu eu pensado em muitos homens e em muitas mulheres, um ilógico de carne e seda, um conflito esculpido em harmonia, luz dorida sobre as ancas estreitas, o dorso deslizante e rijo, a nuca sumarenta, omoplatas lisas como a superfície esquecida de um grande lago nas alturas, docilidade e submissão de uma fêmea enfim subjugada, e aos poucos um macho novamente, altivo e austero, enfiando o sexo na minha boca (HILST, 2003, p. 96).

Percebemos pelo trecho acima que apesar da desestabilização e do deslocamento do gênero aludido no discurso de Lucius, Rútilo Nada (1993) permanece dentro da estrutura binária determinada pela matriz heterossexual. Inclusive, no âmbito das características atribuídas ao que corresponderia a masculino e 
feminino, estando este último sempre relacionado à passividade, subserviência, à delicadeza e espírito dócil, enquanto aquele à altivez, autoridade e domínio. Ainda assim, o livro provoca as noções comuns ligadas à masculinidade, além de mostrar a tendência de encarar o gênero pelo viés do sexuado, tendo os protagonistas um fim trágico e amargo por fugirem dessa predeterminação e desestabilizarem as normas relacionais padrões.

\section{Considerações finais}

Esta pesquisa foi desenvolvida a partir do questionamento central feito a respeito de como os personagens Lucius e Lucas, da narrativa Rútilo Nada (1993), da escritora Hilda Hilst, quebram o pacto com os dispositivos reguladores da matriz heterossexual, sendo a teoria queer aqui utilizada como categoria de análise.

No decurso do trabalho, verificamos que três conceitos primordiais dentro dos estudos queer permeiam o meio social no qual os protagonistas estão inseridos. O primeiro deles é o heterossexismo, e o encontramos nas constantes pressuposições acerca da sexualidade dos personagens, tomando a heterossexualidade por verdade absoluta e obviedade lógica. O segundo, trata-se da heteronormatividade, que se faz presente no livro enquanto modelo, inclusive, quando se faz menção à relação entre duas pessoas do mesmo sexo, estando o binário "homem" e "mulher" como formato de referência. Por fim, a heterossexualidade compulsória mostra-se como principal desencadeador do conflito no conto, uma vez que é a imposição da ordem heterossexual que impede que os personagens permaneçam juntos e acarreta seus finais trágicos. A explanação clara e direta que Richard Miskolci (2012) faz desses conceitos foi de grande utilidade para esta primeira seção.

Vimos logo depois, ainda a partir de Miskolci, mas também de Judith Butler (2003), como por desviarem da norma, ao se envolverem com uma pessoa do mesmo sexo, Lucas e Lucius são relegados a um lugar de abjeção, uma vez que sexo e gênero, em seus casos, não correspondem ao desejo e à prática sexual da forma que a sociedade heteronormativa determina como coerente. Os dois são então reduzidos a uma posição de desprezo, repugnância e de ameaça à estrutura normatizadora.

Posteriormente, relacionamos a narrativa de Hilst às tensões e conflitos que circunscrevem o dispositivo do armário, abordado na obra de Eve Sedgwick (2007), observando como a permanência no armário muitas vezes se impõe às pessoas gays, pois estas têm consciência de que além de afetar as suas vidas, publicizar sua sexualidade também afeta diretamente aqueles de seu convívio 
próximo e familiar. Demos como exemplo a ira do pai de Lucius por ter a sua reputação de banqueiro respeitado posta em risco ao descobrirem que seu filho tem uma relação homossexual.

Por fim, observou-se que em todo o conto as questões de gênero são tratadas pelos personagens de forma naturalizada e naturalizante, reduzindo-se o "ser homem" e o "ser mulher" aos caracteres sexuais, limitando a identidade de gênero ao binarismo masculino e feminino, vinculado a características socialmente determinadas pela matriz heterossexual patriarcal. Portanto, ser homens e se atraírem só por mulheres é o que se espera dos protagonistas de Rútilo, ao passo que isso não acontece, passam, a partir daí, a terem suas masculinidades questionadas e ironizadas. Apesar do binarismo no qual a narrativa é calcada, percebe-se nuances que evidenciam uma desestabilização dessas categorias. Por meio da ótica de Lucius, vislumbra-se o seu referir-se a si mesmo e ao seu parceiro como que transitando de um gênero a outro de forma fluida, o que corrobora com o pensamento defendido por Butler (2003), para quem o gênero não é fixo, mas sim variável e performativo.

Com todo o exposto, concluímos que a trajetória de Lucius e Lucas, em Rútilo Nada (1993), pode ser analisada partindo-se da teoria queer ao mostrar como questões cruciais a esse ramo de estudos estão presentes na narrativa, sendo esta um excelente instrumento de reflexão sobre o abjeto, os conflitos oriundos da relação com o armário, a desestabilização do gênero e o binarismo imposto pela heteronormatividade.

\section{Referências}

AZEVEDO, Aluísio. O Cortiço. Porto Alegre: L\&PM, 2015.

BUTLER, Judith. Problemas de gênero: feminismo e subversão da identidade. Trad. Renato Aguiar. Rio de Janeiro: Civilização Brasileira, 2003.

BENTO, Berenice. Homem não tece a dor: queixas e perplexidades masculinas. Natal: EDUFRN, 2015.

CALEGARI, Lizandro Carlos. A perspectiva queer na literatura brasileira: Aretusa Von e o "Triunfo dos pelos". In: Revista Literatura em Debate, v. 10, n. 18, p. 73-87, ago. 2016.

CAMINHA, Adolfo. Bom Crioulo. São Paulo: Martin Claret, 2009.

CANGUILHEM, Georges. O normal e o patológico. Trad. Maria de Threza Redig de C. Barrocas e Luiz Octávio F. B. Leite. 5. ed. Rio de Janeiro: Forense Universitária, 2002.

DOUGLAS, Mary. Pureza e Perigo: Ensaio sobre as noções de poluição e tabu. Trad. 
Sónia Pereira da Silva. Lisboa: Edições 70 (col. Perspectivas do Homem, n. ${ }^{\circ}$ 39), s.d.

DURKHEIM, Émile.As formas elementares da Vida Religiosa. São Paulo: Paulinas, 1989

FOUCAULT, Michel. Os anormais. Trad. Eduardo Brandão. São Paulo: Martins Fontes, 2002.

FREUD, Sigmund. Três ensaios sobre a teoria da sexualidade. Edição Standard Brasileira das obras completas, vol. VII. Rio de Janeiro: Imago, 1976.

GOUVEIA, Arturo. Escritos Adornianos. João Pessoa: Ideia, 2010.

ROSA, João Guimarães. Grande Sertão: Veredas. Rio de Janeiro: Nova Fronteira, 2001

HILST, Hilda. Rútilo nada. In: HILST, Hilda. Rútilos. São Paulo: Globo, 2003. p. 79-103.

MISKOLCI, Richard. Teoria Queer: Um aprendizado pelas diferenças. Belo Horizonte: Autêntica, 2012.

POMPÉIA, Raul. O Ateneu. São Paulo: Martin Claret, 2001.

SEDGWICK, Eve Kosofsky. A epistemologia do armário. Trad. Plínio Dentzien. Cadernos Pagu, Campinas, n. 28, p. 19-54, jan. jun., 2007.

VON, Aretusa. Triunfo dos pelos. In: VÁRIOS. Triunfo dos pelos e outros contos GLS. Pref. André Fischer; apres. João Silvério Trevisan. São Paulo: Summus, 2000. p. $15-21$. 